\title{
Endovascular aneurysm repair
}

\author{
Proof before publicity
}

I $\mathrm{n}$ the past decade open surgical procedures have been partly replaced by the widespread introduction of laparoscopic and endoscopic techniques. Similar changes have affected vascular surgery, with the development of percutaneous transluminal angioplasty for peripheral atherosclerotic disease. Until recently, the treatment of abdominal aneurysms had relied solely on surgical exposure of the aneurysm and direct graft replacement. However, the recent advent of endovascular aortic aneurysm repair has offered an alternative to conventional surgical practice. ${ }^{1}$ This new technique has been enthusiastically endorsed by vascular surgeons worldwide,,$^{23}$ but, as yet, little proof has been offered to support its widespread introduction.

Endovascular aneurysm repair involves the transfemoral or transiliac placement of a endograft within the aneurysm, with the aim of completely excluding the aneurysm sac from the circulation. The endograft is anchored in place by self expanding or balloon expandable stents, which may support all or part of the graft. The advantages of this technique are principally related to the absence of surgical exposure of the aorta and avoidance of aortic cross clamping, which are both obligatory during direct graft replacement.

The less invasive nature of endovascular aneurysm repair therefore has the potential to reduce the mortality and morbidity of conventional aortic procedures and may offer an opportunity to treat patients with severe coexistent pathologies, who are denied conventional aneurysm repair. ${ }^{4}$ Unfortunately, endovascular techniques are not applicable to all patients with abdominal aneurysms, as a short length of normal aorta is required below the renal arteries to facilitate effective fixation of the endograft. At present about half of aneurysms may be treated by endoluminal repair.

The technical feasibility of performing endovascular aneurysm surgery with acceptable mortality has now been well established by many centres, ${ }^{5}{ }^{6}$ and several complications of this technique have been documented. Like all "minimally invasive" procedures, endovascular aneurysm repair may fail and require conversion to open surgery. The $15-20 \%$ incidence of conversion in early clinical series is likely to fall with experience, but has important implications if endovascular repair is attempted in patients denied conventional surgery due to cardiorespiratory disease.

Postoperative leakage of blood between the endograft and the aneurysm sac ("endoleak") has been reported to occur in about $10 \%$ of cases, and if untreated it may potentially allow persistent expansion and eventual rupture of the aneurysm. Extensive manipulation of large intraluminal devices within the aneurysm sac has also resulted in massive microembolisation, which is refractory to treatment and seems to be uniformly fatal. ${ }^{7}$ This complication may be related to the particular technique used and may reflect the learning curve associated with any new procedure. Future developments in endograft technology and miniaturisation of the delivery systems would be expected to reduce the incidence of embolic complications.

As a new technique, endovascular aneurysm repair has important attractions, but there are clearly specific concerns that must be addressed before widespread clinical application. As the aim of all elective aneurysm surgery is to reduce death from aneurysm rupture, the fate of both the aneurysm sac and the endograft must be determined after endovascular procedures. Preliminary clinical data suggest that only $80 \%$ of aneurysms diminish in size after endoluminal repair. ${ }^{8}$ The rupture rate for these aneurysms remains unknown but may be affected by the presence of late endoleaks. Similarly, the behaviour of the endograft itself requires evaluation as structural failure of stents has already been documented $^{9}$ and the durability of the thin walled graft material used in the endoprosthesis has not been proved by long term follow up.

In the light of these concerns it is clearly essential that endovascular aneurysm repair is prospectively evaluated before the procedure becomes widely accepted as a valid therapeutic technique. Two mechanisms have been proposed to fulfil this function: voluntary registries of procedures undertaken and a prospective multicentre randomised trial. Prospective data registries have been initiated in Britain (RETA) and on a European basis (Eurostar) in order to document safety and efficacy of the technique.

Proponents of collecting non-randomised data suggest that endovascular aneurysm repair cannot be fairly subjected to randomised comparison with conventional surgery, as the endovascular procedure is in its infancy and rapid progress is likely in manufacture and design of endografts. However, endovascular procedures have already been widely documented in the media, and there is increasing pressure on vascular surgeons to provide this facility. Unfortunately, many previous "minimally invasive" techniques have been widely introduced into surgical 
practice before rigorous prospective comparison. ${ }^{10}$ If vascular surgery is not to make the same mistake with endovascular aneurysm repair, a prospective randomised multicentre trial in medically fit patients is essential before the technique is accepted as a valid alternative to conventional aneurysm surgery.

M M Thompson Lecturer

R D Sayers Lecturer

P R F Bell Professor

Department of Surgery, University of Leicester, Leicester LE2 7LX

1 Parodi JC, Palmaz JC, Barone HD. Transfemoral intraluminal graft implantation for abdominal aortic aneurysms. Ann Vasc Surg 1991;5:491-9.

2 Harris PL. Endovascular grafting for abdominal aortic aneurysms. Principles agreed jointly by the Vascular Surgical Society of Great Britain and Ireland and the British Society of Interventional Radiologists for assessment of endovascular grafting techniques and their introduction into clinical practice. Ann R Coll Surg Engl 1996;78(suppl):23-4.
3 Veith FJ, Abbott WM, Yao JS, Goldstone J, White RA, Abel D, et al. Guidelines for development and use of transluminally placed endovascular prosthetic grafts in the arterial system. Endovascular Graft Committee.J Vasc Surg 1995;21:670-85.

4 Thompson MM, Nasim A, Sayers RD, Bell PRF. Endovascular aneurysm repair. Curr Surg Pract 1995;7:21-7.

5 Parodi JC. Endovascular repair of abdominal aortic aneurysms and other arterial lesions.J Vasc Surg 1995;21:549-55.

6 White GH, May J, McGahan T, Yu W, Waugh RC, Stephen MS, et al. Historic control comparison of outcome for matched groups of patients undergoing endoluminal versus open repair of abdominal aortic undergoing endoluminal versus open
aneurysms. J Vasc Surg 1996;23:201-12.

7 Marin ML, Veith FJ, Cynamon J, Sanchez LA, Lyon RT, Levine BA, et al. Initial experience with transluminally placed endovascular grafts for the treatment of complex vascular lesions. Ann Surg 1995;222:449-69.

8 May J, White GH, Yu W, Waugh RC, Stephen MS, Harris JP. A prospective study of changes in morphology and dimensions of abdominal aortic aneurysms following endoluminal repair: a preliminary report. JEndovasc Surg 1995;2:343-7.

9 Balm R, Eikelboom BC, May J, Bell PRF, Swedenborg J, Collin J. Early experience with transfemoral endovascular aneurysm management (TEAM) in the treatment of aortic aneurysms. Eur J Vasc Endovasc Surg 1996;11:214-20.

10 Majeed AW, Troy G, Nicholl JP, Smythe A, Reed MWR, Stoddard CJ, et al. Randomised, prospective, single-blind comparison of laparoscopic versus small-incision cholecystectomy. Lancet 1996;347:989-94.

\section{Allocating donor livers}

\section{Should be given to patients most likely to benefit, irrespective of cause}

$\mathrm{T}$ The furore over new proposals for allocating donor livers in the United States highlights the problems associated with rationing. ${ }^{1}$ The changes, proposed by the United Network for Organ Sharing (UNOS), arose out of a recognition that the existing system was unfair and not the most effective use of a scarce resource. The principles of justice for all and optimal medical use were not being fulfilled. The proposed changes are modest, limited to redefining which patients should have the highest priority and setting criteria for entry on to the waiting list.

Despite greater use of split livers (two liver grafts from one donor) and those from marginal donors (such as those over 60 years, those with hypotension, and non-heart beating donors), the supply of donor livers has remained constant. With more patients being referred for transplantation, the numbers waiting for livers have increased progressively in Europe and North America. Moreover, the wait for a liver has increased, resulting in increased mortality while on the waiting list and a potential increase in perioperative morbidity and mortality. Xenografts may help, but it will some time before they become a clinical reality.

Britain has only seven centres designated by the Department of Health and the Scottish Office for liver transplantation. Under this system it seems preferable to leave the decision as to who should be transplanted when an organ becomes available to the clinicians responsible for managing the waiting list. There is, in general, broad agreement among British transplant centres as to who should or should not receive a transplant.

By contrast the United States has more than 100 transplant programmes. This prevents regular communication between all participating centres. Moreover, transplantation is a "for profit" procedure. Separating financial incentives from the best interests of the patient has, at times, proved difficult. These two factors have created an air of mistrust between transplant centres, which has in turn led to the network's proposals.

There are two strands to the proposed changes. ${ }^{2}$ Firstly, priority should be given to patients with fulminant hepatic failure or with graft failure occurring within seven days of transplantation. In Britain these two indications already comprise the super-urgent list -patients who, by voluntary consent of the designated transplant centres, have priority over all other patients. This priority is based on the narrow time window between identifying with certainty that a transplant is needed and the onset of complications that will either make the transplant technically impossible or increase the risk of substantial neurological or other impairment. A patient with fulminant hepatic failure because of an overdose of paracetamol will get preference over patient with chronic liver disease due to primary biliary cirrhosis.

The American network's argument, based on computer modelling, is different in that it is predicated on outcome. The network believes that giving priority to patients with fulminant hepatic failure is a better use of medical resources since in the United States they have better survival than patients with similarly advanced chronic liver disease. And whereas in Britain children are considered to have the same priority as adults, in the United States children are given priority. Those with chronic liver disease in an intensive care unit and those with hyperammonaemia due to metabolic liver disease are also included in the network's status 1 category.

The second element to the proposed changes are minimal listing criteria. These criteria, which must be met before a patient can be listed for a transplant, were developed for each disease category. Those who do not fulfil the criteria may appeal to a regional review board, which will decide whether listing is appropriate. The network recognises that the minimal listing criteria will need constant revision; however, once the principle is accepted there is no certainty that these criteria will 
reflect only medical priorities. One widely expressed concern is that patients with self inflicted disease, such as alcohol or drug misuse or viral hepatitis acquired as a consequence of non-conventional lifestyles, will be disadvantaged. A proposal requiring a six month minimum period of abstinence has already been withdrawn by the network's board of directors. ${ }^{3}$

Allocating donor livers to ensure optimal use is an aim with which few could disagree, but implementing this principle is problematic. Determining the optimal allocation of organs means making assumptions. Should donor livers be allocated based on greatest need-to the sickest patient, who is also likely to have a higher perioperative mortality-or based on the best outcome - to the fittest patient, who may be able to wait for another donor? Despite the use of sophisticated prognostic models, we do not have the necessary knowledge to apply these models confidently to individual patients. How should we calculate benefit from transplant? Should one, five, or ten year survival be used? Should older people have the same access to scarce livers as younger ones?

Should the patient with self inflicted liver damage have the same priority over those who may be considered "faultless" in the development of liver disease? Patients transplanted for alcoholic disease have, if anything, a better survival than those transplanted for viral hepatitis, despite the fact that patients with alcoholic liver disease are sicker at the time of transplantation. ${ }^{4}$ Should donor livers therefore be allocated preferentially to those with alcohol induced disease? Studies have shown that many patients transplanted for alcoholic liver disease return to alcohol use. However, serious alcohol misuse is uncommon, and damage or loss of the graft, albeit preventable, is rare..$^{5}$

Most transplant clinicians believe that patients should be treated irrespective of the aetiology of liver failure and based on the probability of benefit. ${ }^{6}$ However, it is by no means clear that the public, who not only provide the donor livers but also pay for the procedure, agree. The new proposals for allocating donor livers in the United States represent an important first step towards more open debate about the appropriate use of this scarce resource.

James Neuberger Consultant physician

The Liver Unit, Queen Elizabeth Hospital, Birmingham B15 2TH

John Lake Medical director

UCSF Liver Transplantation Unit, Box 0708, San Francisco, CA 94143, USA

1 Josefson D. US sets new priorities for liver transplants. BMJ 1996;313:1350.

2 United Network for Organ Sharing. Liver allocation policy fact sheet. UNOS:Richmond, Virginia,1996.

3 Steinbrook R. Allocating livers-devising a fair system. NEJM 1997;336:436-9.

4 Howard L, Fahy T, Wong P, Sherman D, Gane E, Williams R. Psychiatric outcome in alcoholic liver transplant patients. OJ Med 1994;87:731-6.

5 Osorio R, Ascher N, Avery M, Bacchetti P, Roberts J, Lake J. Predicting recidivism after orthotopic liver transplantation for alcoholic liver disease. Hepatology 1994;20:105-10.

6 Ghent CN. Overall evaluation: screening and assessment of risk factors. Liver Transplanation and Surgery 1996;2:2-8.

\section{Safe tissue grafts}

\section{Should achieve same standards as for blood transfusion}

$\mathrm{O}$ rthopaedic patients receiving transfusions may worry about the safety of the blood they receive but be blissfully unaware of the possible risks associated with the allograft bone in their femur or hip. Any fears about blood transfusion are largely unfounded. Blood donors in Britain are unremunerated volunteers who are carefully selected and screened by the National Blood Transfusion Service, and donated blood is processed and tracked in a highly regulated environment in which biannual inspections result in the issue of special licenses by the Medicine Control Agency.

Tissue banking in Britain is under no such quality control. In total hip replacements the femoral head, which would otherwise be discarded, may be banked for transplantation to other patients, most commonly in revision hip surgery. ${ }^{1}$ Cadavers provide an alternative source of donor bone. A tissue bank can be established by any organisation without regard to licensing, inspection, or adherence to any standards. There is evidence that many bone banks in hospitals operate suboptimal standards. ${ }^{2}$

Transmission of viral, bacterial, and fungal pathogens has been reported from most types of tissue commonly transplanted. ${ }^{3}$ Testing reduces the risks of transmission, but safety also relies on careful selection of donors on the basis of their medical and social history. The volunteer status of a cadaver tissue donor is clearly not comparable to that of a blood donor. Surgical patients who become tissue donors are actively approached pre-operatively to consider donation, as are the families of potential cadaveric donors. Additional risk arises from the inability to take first hand medical and social histories from those who donate tissues after death. Information must be gleaned from relatives, general practitioners, and pathologists, with particular emphasis on potential transmission of diseases of unknown aetiology, such as sarcoidosis, Parkinson's disease, and malignancy.

Unlike blood, many non-viable tissues can be cleared of bacteria, and possibly viruses, by exposure to ionising radiation or ethylene oxide gas. Even minimal processing of tissues seems to reduce the risk of HIV transmission. ${ }^{4}$ However, when tissue viability is required this is not an option.

These risks must be seen in the context of considerable unmet demand, particularly for allograft bone, which could create pressures to lower the standards of donor selection. Recognising the rapid growth of tissue banking in Britain and the associated risks, the Department of Health conducted a national review. 
Living tissue donors have been required to undergo repeat testing for HIV antibodies, and other markers tested mandatorily in blood donors, 180 days or more after donation, and guidance has been given on the selection and testing of tissue donors, bacteriological safety of donations, storage and transportation of organs and tissues, and the effect of haemodilution of the donor on the validity of tests. ${ }^{5}$

The British Association of Tissue Banks has published standards for the selection, testing, and processing of tissues, ${ }^{6}$ and the association is also developing technical manuals. Many tissue banking activities are undertaken within the National Blood Service in recognition of the similarities between blood and tissue banking. ${ }^{78}$ Guidelines for the Blood Transfusion Service $^{9}$ will shortly include a section on tissue banking, encompassing donor selection, tissue processing, and tracking of tissues from donor to recipient. The tissue banking community is working towards common standards to ensure the safety of tissues for transplantation.

However, common standards alone do not equate with the highly regulated environment in which blood is collected and processed. In the United States, despite the existence of detailed tissue banking standards ${ }^{10}$ and a system of voluntary accreditation, the Food and Drug Administration considered it necessary to introduce legislation governing tissue banking activities. ${ }^{11}$

So where do we stand in Britain? No legislation exists to allow the inspection and regulation of tissue banks. Options include a system of voluntary registration, with peer review against agreed standards, and the inclusion of tissues, with blood, in the brief of the Medicines Control Agency inspectorate. In our view voluntary registration with peer review would be an effective preliminary step towards ensuring the safety of transplanted tissues. This would allow all tissue banks to institute appropriate procedures and documentation. Agreed standards should evolve with time, gradually increasing in their stringency, and should be based on the existing work of the British Association of Tissue Banks and the National Blood Service guidelines. Whether standards comparable to those in the Blood Transfusion Service can be achieved without recourse to legislation and regulation remains to be seen. Whichever option is chosen, it is essential that every patient benefiting from a tissue donation can be confidently reassured that agreed safety standards have been complied with in the provision of the graft.

D Fehily Head of tissue services

R M Warwick Lead consultant for tissue and stem cell donor care

National Blood Service, London and the South East,

North London Blood Centre,

London NW9 5BG

1 Gie GA, Linder L, Ling RSM, Simon J-P, Slooff TJJH, Timperley AJ. Impacted cancellous allografts and cement for revision total hip arthroplasty. J Bone Joint Surg Br 1993;75:14-21.

2 Michaud RJ, Drabu KJ. Bone allograft banking in the United Kingdom.J Bone Joint Surg Br 1994;76:350-1.

3 Eastlund T. Infectious disease transmission through cell, tissue and organ transplantation: reducing the risk through donor selection. Cell Transplant 1995;4:455-77.

4 Simonds RJ, Holmberg SD, Hurwitz RL, Coleman TR, Bottenfield S, Conley LJ, et al. Transmission of human immunodeficiency virus type 1 from a seronegative organ and tissue donor. N Engl J Med 1992;326:72632.

5 Committee on Microbiological Safety of Blood and Tissues for Transplantation, Department of Health. Guidance on the microbiological safety of human tissues and organs used in transplantation. London: NHS Executive, 1996.

6 British Association of Tissue Banks. Standards for tissue banking, June 1995. Transplant Med 1996;6:155-8.

7 Warwick RM, Eastlund T, Fehily D. Role of the blood transfusion service in tissue banking. Vox Sang 1996;71:71-7.

8 Myers SR, Machesney MR, Warwick RM, Cussons PD. Skin storage. National blood transfusion centres could take on skin banking and distribution. BMJ 1996;313:439.

9 Guidelines for blood transfusion service. 2nd ed. London: HMSO, 1994.

10 American Association of Tissue Banks. Standards for tissue banking. Bethesda, MD: American Association of Tissue Banks, 1996.

11 United States Food and Drug Administration: Interim rule: human tissue intended for transplantation. Federal Register. 21 CFR Sect 1270.58:65514-21 (1993)

\title{
Alcohol policy in the Nordic countries
}

\author{
Why competition law must have a public health dimension
}

$\mathrm{L}$ ast month the European Court dealt a potentially fatal blow to alcohol policy in much of Scandinavia. ${ }^{1}$ A preliminary ruling held that Sweden's retail alcohol monopoly, which has the effect of controlling access to spirits, was illegal under European competition law. If upheld, this policy seems likely also to apply to Finland and, possibly, Norway and Iceland due to their obligations as members of the European Economic Area. All of these countries operate this system, which has been effective-death rates from cirrhosis in Sweden are less than half those in Denmark, where there is no such policy. ${ }^{2}$

Indeed, in February the Danish daily newspaper Politiken reported new evidence that deaths from alcohol related diseases in Denmark have risen by 120\% since $1970,{ }^{3}$ contributing to the failure of Denmark to match improvements in life expectancy seen in neighbouring countries. ${ }^{4}$ The death rate from liver cirrhosis in Denmark is now as high as in France, ${ }^{2}$ a country where drinking has historically been at a higher level. These findings are consistent with evidence from sales figures. These underestimate consumption, as they exclude alcohol bought in duty free shops or elsewhere in the European Union, but they show that consumption in Denmark has risen by $36 \%$ between 1970 and 1993.

The situation in Denmark deserves close attention. The Danish government, while recognising the adverse health consequences of excess alcohol consumption, has avoided regulatory approaches such as the controls on access used in other parts of Scandinavia and instead relies on taxation. Taxation does reduce demand, ${ }^{5}$ but this should be part of a comprehensive strategy including a range of policy instruments. Furthermore, the effect of a policy should be monitored and, if it is not working, changed. It is now 
clear that this policy has failed and there is an urgent need for a new approach.

Unfortunately, even before the court's decision, there was evidence that things could become worse. Denmark was one of the first countries to introduce a safe drinking campaign, based on new evidence that moderate consumption of alcohol may confer some protection against cardiovascular diseases. There are several reasons why this may be inappropriate in general and in the Danish context in particular. The first relates to the distribution of alcohol consumption in the population. When there is already evidence of substantial alcohol consumption, with many people drinking at levels that damage their health, relaxing "official" guidelines may move the entire distribution so as to increase the population at risk of adverse consequences. ${ }^{6}$ Further evidence of this comes from the paper by Colhoun and others in this week's issue (see p 1164). ${ }^{7}$

Secondly, the size of the overall beneficial effect of moderate drinking is not the same for all age groups, and, for some conditions such as strokes, ${ }^{89}$ it is not seen. Although Denmark has had low death rates for cerebrovascular diseases, virtually no improvement occurred in the past few decades. ${ }^{10}$ There is clear evidence that Denmark is now losing its advantage, with many other countries reaching lower levels of mortality.

Although there seems a clear need for action, evidence from other countries suggests that key decisions often reflect considerations other than the impact on health. ${ }^{11}$ For example, the recent relaxation of alcohol consumption guidelines by the British government has been heavily criticised because of the influence exerted by the alcohol industry. ${ }^{12}$ It is less clear how much this is the case in Denmark, although we cannot ignore the prominent part played by the industry in the Danish economy and in social and cultural life. It is a major employer and contributes directly - through taxes and provision of some homes for elderly people - and indirectly - through the contribution of exports and employment-to the broader economy. It thus has considerable lobbying power, and it is difficult to see any government wishing to alienate it.
The European Court's decision is consistent with the tremendous pressure by some countries in the European Union, most notably Britain, to promote deregulation and further liberalisation in many areas of public life and highlights the dangers to public health posed by competition law unconstrained by adequate public health safeguards-not only at a European level but also, potentially more importantly, through the World Trade Organisation. The Danish experience of the past two decades adds to the evidence $^{13}$ that this road is a dangerous one and one that must be addressed at the forthcoming intergovernmental conference on the future development of the European Union.

\section{Laurent Chenet Research fellow}

Martin McKee Professor of European public health

European Centre on Health of Societies in Transition, London School of Hygiene and Tropical Medicine,

London WC1E 7HT

Merete Osler Lecturer

Allan Krasnik Professor of social medicine

Institute of Public Health, 2200 Copenhagen N, Denmark

1 McIvor G, Tucker E. Court blow to Swedish liquor monopoly. Financial Times 1997 March 5:2.

2 World Health Organisation. HFA database. Copenhagen: WHO, 1997.

3 Inge Methling 1997 Stadig flere doer af druk. Politiken 1997 February $14: 2$.

4 Chenet L, Osler M, McKee M, Krasnik A. Changing life expectancy in the 1980s: why was Denmark different from Sweden? J Epidemiol Community Health 1996:50:404-7.

5 Edwards G, Anderson P, Babor TF, Casswell S, Ferrence R, Giesbrecht N et al. Alcohol policy and the public good. Oxford: Oxford University Press, 1994.

6 Rose G. Strategy of prevention: lessons from cardiovascular diseases. $B M$ 1981;282:1847-51.

7 Colhoun H, Ben-Shlomo Y, Dong W, Bost L, Marmot M. Ecological analysis of collectivity of alcohol consumption in England: importance of average drinker. BMJ 19978;314:????-?

8 Doll R, Peto R, Wheatley K, Gray R, Sutherland I. Mortality in relation to smoking: 40 years' observations on male British doctors. BMJ 1994;309:901-11.

9 Yuan J, Ross RK, Gao Y, Henderson BE, Mimi CY. Follow up study of moderate alcohol intake and mortality among middle aged men in Shanghai, China. BMJ 1994;314:18-23.

10 World Health Organisation. Highlight on health in Denmark. Copenhagen: WHO Regional Office for Europe, 1996.

11 McKee M, Lang T. Secret government: the Scott report. Links with industry cast doubt on the government's role in public health. $B M J$ 1996;312:455-6

12 Edwards G. Sensible drinking. BMJ 1996;312:1.

13 McKee M, Lang T, Roberts J. Deregulating health: policy lessons of the BSE affair. JR Soc Med 1996;89:424-6.

\title{
Women's autonomy in childbirth
}

\author{
We may advise and persuade, but never coerce
}

See $\mathrm{p} 1183$

$\mathrm{T}$

he lay and medical press have recently hosted a vigorous debate over enforced caesarean sections. At least six cases have been reported in the past six months, of which one, albeit an unusual one, is discussed in this week's BMJ (p 1183). ${ }^{1}$ A landmark judgment from the court of appeal this March has clarified the legal position: a mentally competent patient has an absolute right to refuse medical treatment even where that decision might lead to her death or the death of her baby, for any rational or irrational reason or for no reason at all. What this means is that unless capacity to consent is at issue, the courts are unlikely to consider future applications of this kind. The capacity to consent is assumed to be present until it is shown not to be, and is quite distinct from mental health or rationality. ${ }^{2}$ This still leaves some obstetricians feeling uncomfortable.

In this week's $B M J$ four sets of commentators discuss one of the earlier cases, where doctors' perceived ethical duty to rescue a threatened fetus came into conflict with the mother's wishes. ${ }^{1}$ The case is unusual in that the order enabling an enforced caesarean section on a woman with schizophrenia was granted under the Mental Health Act, rather than 


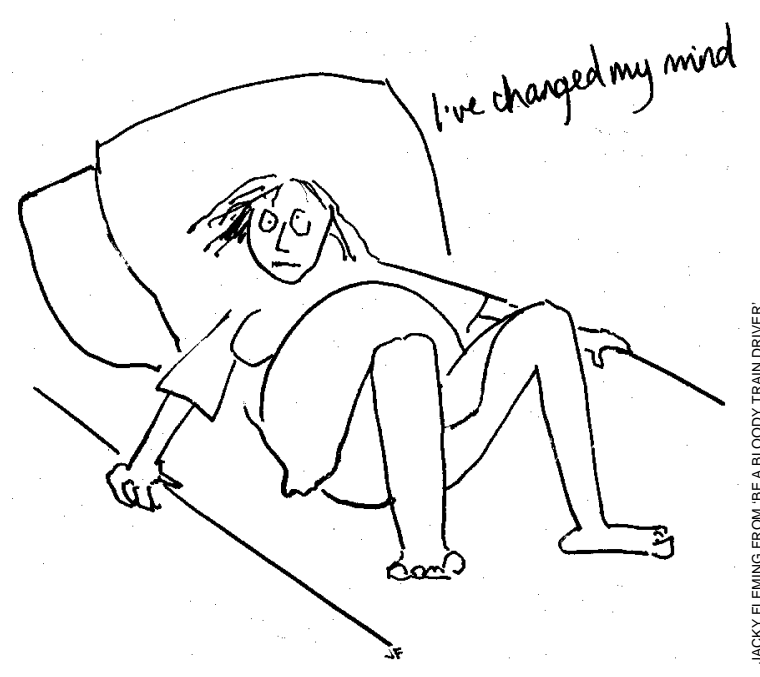

under common law. We asked an obstetrician, a barrister, two ethicists, and two patient representatives to comment, and unusually, they are unanimous in their condemnation of the judgment. Instead of sticking to what obstetrician Susan Bewley refers to as the time honoured and legitimate weapon of "heavy duty persuasion," doctors in Tameside and Glossop sought a court order which led to an unprecedented use of the Mental Health Act.

Forensic psychologist Bridget Dolan and Camilla Parker, legal officer of the mental health charity Mind, believe the judgment makes bad law. "The Mental Health Act was intended to provide a balance between the desire of clinicians to provide (psychiatric) treatment and the right of patients to make decisions about their treatment. It certainly was not intended to override the rights of women to decide on their obstetric care," they argue. Susan Bewley believes it was also bad medicine, contravening the Royal College of Obstetricians and Gynaecologists" guidelines, which state that a woman's wishes must be taken into account even if she is incompetent for the purposes of consent. ${ }^{3}$ There can be no trust between women and their obstetricians, she argues, if women fear coercion.

According to barrister Adrian Whitfield, clinicians faced with this type of ethical dilemma sometimes "allow their hearts to rule their heads," disregarding the fact that the unborn child has no legal status under common law, and the courts "no jurisdiction to take the interests of the fetus into account and balance them against those of the mother." That the patient had no proper legal representation is a worrying twist emphasised by patient representatives Hilda Bastian and
Cathy Conroy, who argue that seeking such a ruling had as much to do with "medical paranoia" as with the woman's state of mind.

We are left wondering why obstetricians are turning to the courts to sanction compulsory treatment, and why now? Perhaps it is to do with societal change and medical reaction. Nowhere than in obstetrics is it clearer that paternalism from doctors is decreasingly acceptable to patients, yet obstetricians must struggle to square this with their role as "passionate advocates of fetal health and wellbeing." The medical vigilance which has helped to reduce perinatal and maternal morbidity and mortality sometimes rests uneasily with a woman's enfranchisement in her own care. Perhaps modern women are too comfortably unaware of the dangers faced in childbirth by their great grandmothers, and the frustration this engenders in doctors sends them running to the courts for support. The distress associated with labour would appear, superficially, to justify this approach; after all, to take literally every appeal from an exhausted woman of, "I can't" or, "Just do a caesarean section" would equally be to fail her. So with fear of negligence litigation on the one hand and an increased awareness of the need for informed consent on the other, doctors (and healthcare trusts) feel impotent where they are most responsible.

But the Cumberledge report on changing childbirth has made society's mandate absolutely clear: women are to be at the centre of decisions surrounding their obstetric and midwifery care. ${ }^{4}$ The legal underpinning of this is now also clearer than ever. Sometimes the best obstetric care will be declined, with disastrous consequences, and nothing goes harder with an obstetrician than to listen passively to a decelerating fetal heartbeat. But our duty is to respect a woman's autonomy and obey the law. Doctors, midwives, and childbirth educators must advise fully and honestly, may persuade, but may never coerce.

Sandra Goldbeck-Wood Assistant editor

BMJ, London WC1H 9JR

1 Dolan B, Parker C, Bewley S, Whitfield A, Bastian H, Conroy C. Tameside and Glossop Acute Services Trust $v$ CH (a patient) [1996] 1 FLR 762. BMJ 1997; 314:1183-7.

2 Dyer C. Appeal court rules against compulsory caesarean sections. BMJ 1997;314:993.

3 RCOG guidelines. Ethics. A consideration of the law and ethics in relation to court-authorised obstetric intervention. No 1. London: Royal College of Obstetricians and Gynaecologists, 1994. (Supplement to No 1 published in December 1996.)

4 Cumberledge J. Changing childbirth. London: HMSO, 1993 